\title{
“CANVAS” E O MODELO JURÍDICO DE NEGÓCIOS
}

Frederico de AndRade Gabrich

Doutor, Mestre e Especialista em Direito Empresarial/Comercial pela UFMG. Professor Adjunto da Universidade FUMEC - BH - MG. Designer de ideias.

\section{Resumo}

Não existe ideia, negócio ou empresa, de controle privado ou público, que não exija uma adequada estratégia jurídica para ser implementada com a máxima eficiência possível. Por isso, náo há como efetivamente conhecer os ramos do Direito que se relacionam diretamente com a organização empresarial, sem a análise da lógica de planejamento e de execução das ideias geralmente utilizada pelas empresas. Mais do que isso, é fundamental a combinação entre a modelação e o planejamento empresarial, com o adequado e correspondente planejamento jurídico estratégico dos objetivos empresariais. Dai a necessidade e a importância do desenvolvimento de um Modelo Jurídico de Negócios que possa ser usado de forma combinada com o Quadro Modelo de Negócios ou Canvas.

\section{Palavras-chave}

Análise Estratégica do Direito; Modelo de Negócios; Canvas; Modelo Jurídico de Negócios.

\section{Abstract}

There is no idea, business or company, private or public control, which does not require an appropriate legal strategy to be implemented as efficiently as possible. Therefore, there is no way actually know the areas of law that are directly related to the business organization, without analysis of the planning logic and implementation of ideas generally used by companies. More than that, the combination of modeling and business planning is essential, with appropriate legal and related strategic planning of business objectives. So it's the need and the importance of developing a Legal Business Model that can be used in combination with Canvas.

\section{Key words}

Strategic Analysis of Law; Business Model; Canvas; Legal Business Model. 


\section{Introdução}

A lógica de organização dos bens de produção dentro de uma empresa é global e também globalizante. Nos dias atuais, a maioria absoluta dos negócios e das empresas espalhadas pelo planeta organizam-se de maneira muito parecida, com a estruturação estratégica do capital e do trabalho.

É importante observar, contudo, que a maioria absoluta dos negócios (em todo o mundo) começa com uma ideia, formulada ou construída por uma ou por várias pessoas.

Ocorre que, em muitos casos, as pessoas que formulam a ideia não possuem todos os demais elementos necessários à sua implementação eficaz, tais como, dentre outros, o tempo, as pessoas, a tecnologia, o dinheiro etc.

É exatamente a conjunção de todos esses diversos fatores que permite não apenas a concretização dos negócios, mas, também, a realização da atividade empresarial global.

A organização dos elementos da empresa pressupóe a determinação de objetivos e a elaboração de um ou de vários modelos de negócios, seguidos de uma estratégia, de um plano completo de negócios, e de um número também significativo de planos de ação. Após a formulação da ideia, a elaboração de um modelo de negócios exige, basicamente, estabelecer ordem para a execução da ideia, com a identificação do(s) segmento(s) de clientes que se pretende atender, a construção da proposta de valor que será entregue aos clientes determinados, bem como os modos e os canais de relacionamento com a clientela, as fontes de receitas, as atividades essenciais, os recursos fundamentais, as principais parcerias possíveis e a estrutura de custos.

Contudo, não basta apenas o macroplanejamento do negócio, mas a sua mais eficiente realização, que implica o menor custo possível de desgaste psicológico, de tempo e de dinheiro. E isso pressupóe a conjunção de ideia, modelo de negócios, planejamento estratégico, plano de negócios e de planos de ação, estruturados na esfera organizacional, financeira, comercial, mercadológica e, também, jurídica.

Não existe ideia, negócio ou empresa, de controle privado ou público, em qualquer país ou continente, que não exija uma adequada estratégia jurídica para ser implemen$\operatorname{tada}($ o) com a máxima eficiência possível. Por isso, não há como efetivamente conhecer os ramos do Direito que se relacionam diretamente com a organização empresarial (com destaque para o Direito Empresarial, o Direito Civil - obrigaçóes e contratos, o Direito Tributário e o Direito do Trabalho), sem a análise da lógica de planejamento e de execução das ideias geralmente utilizada pelas empresas. Mais do que isso, é fundamental a combinação entre a modelação e o planejamento empresarial, com o adequado e correspondente planejamento jurídico estratégico dos objetivos empresariais. Dai a necessidade e a importância do desenvolvimento de um Modelo Jurídico de Negócios que possa ser 
usado de forma combinada com o Quadro Modelo de Negócios ou Canvas, pois o Direito Empresarial ou Mercantil não pode ficar alheio à lógica atual de organização e de gestão da empresa contemporânea.

\section{Ideia, Modelo de Negócios, Planejamento Estratégico, Plano de Negócios}

Como foi mencionado no introito, a maioria absoluta dos negócios começa com uma ideia, formulada ou construída subjetivamente por uma ou por várias pessoas. A ideia pode ser original, inovadora e determinar o início da vida ou do ciclo de um novo produto, de um novo serviço, em um novo mercado, ou apenas ser desenvolvida para aprimorar aquilo que já existe. Mas, em qualquer caso, de forma expressa ou implícita, a ideia somente se transforma em um produto ou serviço para ser oferecido em um determinado mercado, de forma sustentável e perene, após a elaboração de um modelo de negócios que, por sua vez, deve estar conectado com uma lógica maior de planejamento e de gestão estratégica da organização empresarial. Tudo isso reunido é que forma um plano de negócios, em suas diversas etapas.

De fato, em um ambiente de negócios extremamente competitivo, como o que se estabeleceu a partir da segunda metade do Século XX, as organizaçóes passaram a orientar as suas açóes cada vez mais para obterem vantagens competitivas capazes de lhes garantir a sobrevivência e a prevalência nos mercados de produtos e de serviços nos quais elas atuam.

Estabeleceu-se, assim, primeiro nas empresas, um processo de administração estratégica composto por um conjunto de compromissos, decisóes e açóes necessárias para que elas obtenham vantagem competitiva e retornos maiores e acima da média (HITT, IRELAND, HOSKISSON, 2011, p. 6). Essa realidade empresarial, com o tempo, em alguns casos de maneira evidente e em outros de forma subliminar, também passou a ser observada na organização administrativa do Estado, que muitas vezes convive com realidades tipicamente empresariais, com o excesso de demanda por serviços (públicos) de qualidade, em um ambiente de escassez de recursos (tecnológicos, humanos, financeiros). Daí a imperiosa necessidade de também o Estado, em sua atuação direta e indireta, obter retornos acima da média (não necessariamente medidos pelo viés exclusivamente financeiro), o que pode ser viabilizado por meio de um processo de planejamento e de administração estratégica.

Com a realidade inexorável da globalização, da interdependência de todos os agentes econômicos (públicos e privados) e dos mercados mundiais, estabelece-se, no âmbito das organizaçóes, a lógica darwinista que impóe a sobrevivência dos mais fortes, dos mais organizados, dos mais eficientes (LOBATO et al, 2005, P. 33). E isso é mais evidente nas organizaçóes que planejam e que executam todas as suas açóes por meio de uma gestão estratégica competitiva, com enfoque mais integrado, menos centralizado e mais sistêmico 
das funçôes administrativas. Basicamente, a gestão estratégica competitiva das organizaçôes contemporâneas pressupóe a definição das diretrizes ou premissas estratégicas (valores, visão, missão), a análise dos ambientes externo (oportunidades e ameaças) e interno (forças e fraquezas), a análise da concorrência (rivalidade entre as empresas existentes), bem como dos produtos/serviços substitutos, do poder de negociação dos fornecedores e dos compradores, além da análise da ameaça de potenciais entrantes no mercado (PORTER, 1986, p. 23), sendo tudo combinado com a aplicação das principais ferramentas estratégicas, o que implica a formulação de objetivos, a definição de metas, a identificação de indicadores de desempenho, a formulação, a implementação e o monitoramento dos planos de ação. Tudo inserido em uma lógica sistêmica que considere os interesses dos stakeholders, as especificidades de cada unidade de negócio, os fatores críticos de sucesso.

Contudo, antes mesmo de se estabelecer formal e explicitamente um plano de negócios integrado e total, é preciso o desenvolvimento e a organização de um modelo de negócios, seguido de planejamento e de gestão estratégica das açóes empresariais que permitam, de forma integrada, a plena realização da ideia e a sua efetiva transformação em um produto e/ou serviço que seja valorizado em um determinado mercado e em um dado momento. Nesse sentido, a estruturação teórica do modelo de negócios é o passo seguinte à formulação da ideia inicial (preferencialmente inovadora) que deverá ser transformada em um produto e/ou em um serviço. De fato, entender e definir o modelo de negócios é absolutamente fundamental para se estabelecer, na sequência, a estratégia empresarial e o plano de negócios que será implementado no desenvolvimento efetivo e mais eficiente possível da atividade econômica (privada ou pública).

De fato, o Plano de Negócios é um documento normalmente usado para descrever o negócio em detalhes e serve para que a empresa se apresente diante dos fornecedores, investidores, clientes, parceiros, empregados etc. (BIAGIO e BATOCCHIO, 2012, p. 3).

Assim, segundo NOGUEIRA e ALMEIDA (2011),

[o] plano de negócios é um documento de planejamento, elaborado de acordo com as necessidades de cada empreendimento, capaz de mostrar toda a viabilidade e as vantagens competitivas de um empreendimento, do ponto de vista estrutural, administrativo, estratégico, mercadológico, técnico, operacional e financeiro. É um documento usado para descrever o negócio e apresentar a empresa aos fornecedores, investidores, clientes, parceiros, empregados etc.

Para WILDAUER (2011, p. 39):

Podemos então resumir o plano de negócios como um documento no qual o empreendedor apresenta, em linguagem formal e objetiva, o negócio que quer conceber e propor para seus parceiros, sócios e futuros investidores, expondo-lhe a visão, a missão e os objetivos do empreendimento, 
bem como o plano operacional (como irão funcionar as ideias), o plano de marketing (para divulgação das ideias), o plano financeiro (para captação, manutenção e distribuição de verbas) e o plano jurídico (como respeitará as leis e regulamentos do setor), de modo a facilitar o entendimento e a aceitação do negócio por parte dos interessados.

Não obstante, segundo BIAGIO e BATOCCHIO (2012, p.4):

O plano de negócios permite avaliar os riscos e identificar soluções; definir os pontos fracos e fortes da empresa em relação aos concorrentes; conhecer as vantagens competitivas da empresa; identificar aquilo que agrega valor para o cliente, ou seja, quais características os clientes procuram nos produtos e serviços pelos quais estâo dispostos a pagar; planejar e implantar uma estratégia de marketing voltada ao cliente-alvo; estabelecer metas de desempenho para a empresa e avaliar investimentos; identificar as necessidades de absorção de novas tecnologias e novos processos de fabricaçáo; e calcular o retorno sobre o capital investido, a lucratividade e a produtividade. Enfim, o plano de negócios é um guia que norteará todas as açóes da empresa.

Dessa maneira, o plano de negócios compreende uma visão bastante ampla do negócio, que compreende não apenas a ideia e o modelo específico do negócio que irá permitir transformá-la em um produto ou serviço, mas também a estrutura jurídica, administrativa, financeira, comercial, bem como o planejamento estratégico e todos os planos de açáo necessários à sua realização.

Nesse sentido, também segundo NOGUEIRA e ALMEIDA (2011),

O planejamento estratégico está inserido no plano de negócios e não deve ser trabalhado isoladamente como tem acontecido por força do modismo, tendo em vista que informaçóes valiosas sobre a organização estão além desta etapa, mas contempladas em todo o conjunto do planejamento da organização, que é o plano de negócios. Sem as informaçôes completas, qualquer decisão aleatória poderá ser subentendida que é fruto de uma análise infundada e empírica sem um raciocínio lógico e sequenciado que conclua a realidade do que é de fato a organização e o mercado em que está inserida e assim será falha e poderá causar o fracasso da empresa. Um planejamento estratégico bem elaborado é composto de: visão, missão, cadeia de valores, competências essenciais, análise das oportunidades e ameaças, análise dos pontos fortes e fracos, definição dos objetivos e das metas, formulação e implementação das estratégias, controle e retorno das informações.

Assim, o Plano de Negócios é mais amplo do que o Modelo de Negócios e visa transmitir uma macro perspectiva do empreendimento empresarial. Por isso, da mesma maneira como ocorre com a ideia inicial e com o planejamento estratégico, o próprio 
Modelo de Negócio e as estratégias jurídicas, financeiras, administrativas, comerciais etc, também estão inseridas no Plano de Negócios, que deve ser efetivamente usado como um guia, como um plano de voo para empresa, e não apenas como uma apresentação formal usada exclusivamente para captação de fontes de financiamento (BIAGIO e BATOCCHIO, 2012, p. 4). Mas o plano de negócios, sozinho, não garante o sucesso da empresa ou a sua lucratividade. Todavia, quando o plano de negócios é desenvolvido com qualidade, aumentam muito as chances de sucesso do empreendimento (BERNARDI, 2011, p. 4).

\section{Business Model Generation: Canvas}

De fato, na construção de um Plano de Negócio e na efetiva construção de uma empresa, imediatamente após a formulação da ideia e antes mesmo da elaboração de um planejamento estratégico, faz-se necessária a formulação de um modelo de negócios.

Conforme expóe BERNARDI (2011, p. 25):

Modelos são representações hipotéticas de um sistema, e seu desempenho está relacionado a variáveis controláveis e incontroláveis, uma rede de interaçôes e inter-relaçôes em estado dinâmico e numa simbiose. À medida que se modela um sistema, a concepção do modelo e o processo de desenvolvimento fazem com que o experimentador se torne autoconsciente, numa integração de atitudes, de conceitos e de valores que influenciam o entendimento, o planejamento, a ação e a reação dos elementos do sistema. Os pressupostos do sistema e os objetivos implícitos influenciam a configuração e o desenho do modelo. Ao modelar e estruturar uma empresa, o resultado está diretamente relacionado aos objetivos, à composição do sistema e à visão que se tem do papel da empresa no sistema macro, bem como nos valores incorporados. A concepção de um modelo empresarial é determinada basicamente por dois propósitos: competitivo -egocêntrico e sistémico-holístico.

Não obstante, nos tempos atuais, a maioria das empresas e dos negócios oferecem quase os mesmos produtos e quase os mesmos serviços, por preços cada vez mais parecidos. Por isso, a diferenciação dos produtos, dos serviços e das empresas, cada vez mais, precisa ser estabelecida por meio de inovaçóes que seduzam os consumidores no momento da compra e durante a toda a experiência de uso/consumo. A inovação, por isso, passou a ser um dos elementos mais importantes e decisivos para a construçáo e para a manutenção do sucesso de um negócio.

Nesse contexto, o processo de design de ideias inovadoras pressupóe atualmente não apenas a criação de produtos e de serviços novos ou mais eficientes, mas também de modelos de negócios inovadores e competitivos, que precisam ser simples, intuitivos e 
conectados náo apenas com as necessidades, desejos e vontades (racionais e emocionais) dos consumidores, mas também com os interesses mais amplos de sustentabilidade da vida no planeta.

Foi exatamente para atender à necessidade de criação, (r)evolução e explicitação simples, direta e inovadora dos modelos de negócios, que Alexander Ostenwalder e Yves Pigneur desenvolveram o Business Model Generation, descrito no livro Inovação em Modelos de Negócios: um manual para visionários, inovadores e revolucionários, e que tem sido usado nos dias atuais, cada vez mais, como marco teórico estruturante dos modelos de negócios desenvolvidos por empresas de diversos setores e tamanhos, em todo o mundo.

Assim, de acordo com OSTERWALDER e PIGNEUR (2013, p. 14-15), "um modelo de negócios descreve a lógica de criação, entrega e captura de valor por parte de uma organização". Por isso, "o modelo de negócios é um esquema para a estratégia ser implementada através de estruturas organizacionais dos processos e sistemas.". Segundo esses autores, o conceito de modelo de negócios precisa se transformar em uma linguagem comum que permita náo apenas o reconhecimento do negócio proposto a partir de uma ideia, mas a descrição, a visualização, a avaliação e a manipulação que permita a criação de novas estratégias. Entender e definir um modelo de negócios é fundamental, então, para que depois sejam estabelecidas todas as estratégias que devam ser implementadas no curso da empresa.

OSTERWALDER e PIGNEUR (2013) propóem, basicamente, a utilização de nove componentes fundamentais de um modelo de negócios, para formar a base de uma ferramenta útil, simples e intuitiva que denominam de Quadro Modelo de Negócios ou Canvas. Segundo os autores:

Esta ferramenta lembra uma tela de pintura - mas pré-formatada com nove blocos - que permite criar imagens de Modelos de Negócios novos ou já existentes. $\mathrm{O}$ quadro funciona melhor quando impresso em uma grande superfície, para que vários grupos de pessoas possam rascunhar e discutir juntos os seus elementos, com anotaçôes em adesivos (Post-it) ou marcadores. É uma ferramenta prática e útil que promove entendimento, discussão, criatividade e análise. (OSTENWALDER e PIGNEUR, 2013, p. 42) (grifos no original).

Basicamente, os nove componentes do Canvas proposto por Osterwalder e Pigneur são os seguintes: (1) segmentos de clientes, (2) proposta de valor, (3) canais, (4) relacionamento com clientes, (5) fontes de receita, (6) recursos principais, (7) atividades chave, (8) parcerias principais, (9) estrutura de custo.

A representaçáo gráfica e visual do Quadro Modelo de Negócios (Canvas) proposto por Osterwalder e Pigneur, geralmente é descrita da seguinte maneira: 


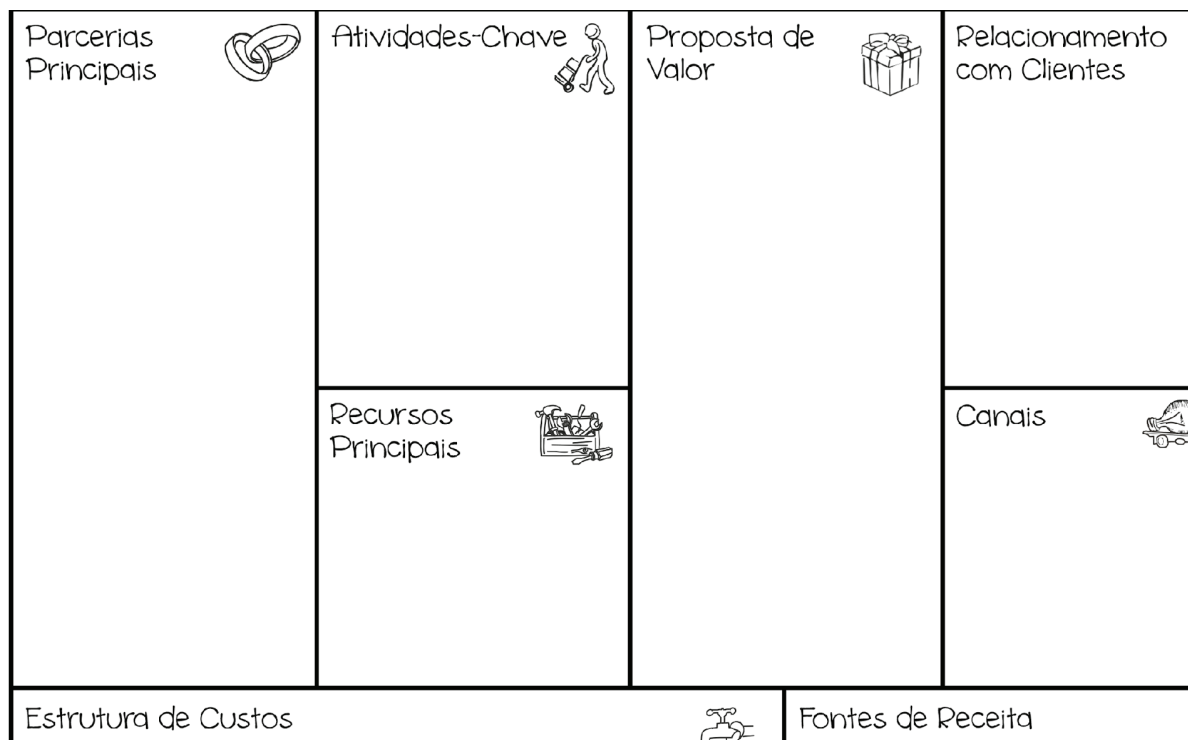

De fato, a grande vantagem do Quadro Modelo de Negócios é permitir a comunicação visual e integral de todos os elementos fundamentais do modelo de negócios proposto, o que facilita, sobretudo, a compreensão da dimensão do negócio da empresa, bem como o desenvolvimento mais eficiente do plano de negócios, do planejamento estratégico e dos respectivos planos de ação. Sem dúvida, as pessoas reagem mais e melhor àquilo que compreendem e visualizam, e essas são exatamente as grandes vantagens do Canvas. O Quadro Modelo de Negócios acaba sendo um importante instrumento de comunicação tanto para as pessoas responsáveis pela efetivaçáo do negócio, quanto para os clientes e o mercado.

\subsection{Segmentos de Clientes}

Na construçáo de um Quadro Modelo de Negócios ou Canvas, o primeiro elemento que deve ser considerado pela empresa ou pelo(a) empresário(a) são os segmentos de clientes que são ou serão atendidos pelo negócio. No campo segmento de clientes é necessário definir os diferentes grupos de pessoas (naturais e/ou jurídicas) que a empresa busca atender ou servir, e que devem ser agrupados de maneira distinta dependendo de diversos fatores, tais como, dentre outros: classe social e cultural, disponibilidade de recursos financeiros, as necessidades atuais e futuras dos clientes, os canais de distribuiçấo que serão usados para atingi-los, os diferentes tipos de relacionamento necessários para atendê-los, a lucratividade diferente em cada segmento de cliente, a disposição psicológica e financeira dos clientes para valorização e para pagamento dos diversos aspectos da oferta 
Conforme OSTERWALDER e PIGNEUR (2013, p. 20) esclarecem,

Os clientes são o âmago de qualquer Modelo de Negócios. Sem clientes, nenhuma empresa pode sobreviver por muito tempo. Para melhor satisfazê-los, uma empresa precisa agrupá-los em segmentos distintos, cada qual com necessidades comuns, comportamentos comuns, e outros atributos comuns. Um Modelo de Negócios pode definir um ou vários segmentos, pequenos ou grandes. A organização deve tomar uma decisão consciente sobre quais segmentos servir e quais ignorar. Uma vez tomada a decisão, um Modelo de Negócios pode ser melhor projetado já com a compreensão das necessidades de clientes específicos.

De fato, a definição dos segmentos de clientes que serão atendidos pressupóe responder a pelo menos duas perguntas: (i) para quem a empresa ou negócio cria ou vai criar valor? (ii) quem são ou serão os consumidores mais importantes da empresa ou negócio?

De qualquer maneira, a definição do campo segmento de clientes do Quadro Modelo de Negócios pressupóe reconhecer que existem diferentes tipos de clientes, inseridos em mercados de massa (grupo uniforme de clientes com necessidades, problemas e desejos similares), em nichos de mercado (clientes específicos e especializados), em segmentos de mercado sutilmente diferentes (clientes com necessidades e problemas similares, mas variados e um pouco diferentes), em mercados diversificados (clientes com necessidades e problemas muito diferentes), em mercados multilaterais (segmentos de clientes com necessidades e problemas muito diferentes, como, por exemplo, os compradores de livros e as empresas de web que utilizam, ambos, a estrutura de tecnologia da informação da Amazon).

Sendo diversos os Segmentos de Clientes possíveis para um negócio ou empresa, variadas também devem ser as estratégias (inclusive jurídicas) que irão sustentar a efetivação do negócio.

\subsection{Proposta de Valor}

O segundo campo ou elemento que deve ser preenchido na composiçáo do Canvas é aquele relativo à Proposta de Valor, que pode ser composto por uma ou diversos itens, direcionados para um ou para os diversos Segmentos de Clientes definidos antes no campo específico.

No campo relativo à Proposta de Valor do quadro modelo de negócios, o mais importante é descrever o pacote de produtos e/ou de serviços que a empresa irá oferecer ou já oferece para criar valor para cada Segmento de Cliente específico, pois, segundo OSTERWALDER e PIGNEUR (2013, p. 22): 
A Proposta de Valor é o motivo pelo qual os clientes escolhem uma empresa ou outra. Ela resolve um problema ou satisfaz uma necessidade do consumidor. Cada Proposta de Valor é um pacote específico que supre as exigências de um Segmento de Clientes específico. Nesse sentido, uma Proposta de Valor é uma agregação ou conjunto de benefícios que uma empresa oferece aos clientes.

Para isso, dentre outras, os responsáveis pelo negócio ou empresa precisam responder a algumas perguntas, tais como, por exemplo, (i) o que os nossos clientes precisam ou desejam neste momento ou no futuro? (ii) quais são os problemas que os nossos clientes têm e precisam resolver? (iii) que conjunto de produtos e/ou serviços podemos oferecer aos nossos clientes para satisfação dos desejos, necessidades, vontades e problemas deles?

Como OSTERWALDER e PIGNEUR esclarecem (2013, p. 23), uma Proposta de Valor poder ser quantitativa (preço, rapidez no atendimento ao cliente) ou qualitativa (design, experiência oferecida ao cliente), mas sempre marcada por algumas características, tais como, dentre outras, novidade ou inovaçáo (incremental ou radical), desempenho (maximização dos resultados alcançados com o produto ou serviço), personalização (customização e adequação às necessidades específicas dos clientes individualmente considerados ou por segmentos), design (forma + função), marca (geralmente valorizadas pelos clientes como resultado de investimentos em marketing), status (efeito condecoração percebido pelos clientes que exibem com orgulho os produtos/serviços adquiridos ou usufruídos), preço (alto, baixo ou até gratuito), redução de custo (maximização de tempo, de desgaste psicológico e de dinheiro), mapeamento e controle de risco (estabilidade no uso do produto ou serviço comprado), acessibilidade (para muitas pessoas, independentemente das características individuais de cada uma), sustentabilidade (produtos e serviços que não comprometam a vida no planeta Terra), conveniência (valorização do comodismo e da facilidade de uso), usabilidade (interatividade e uso "amigável" do produto/ serviço) etc.

Do ponto de vista de estruturação jurídica do negócio ou da empresa, essas características da Proposta de Valor são muito importantes, pois, a partir delas, será possível estabelecer uma estratégia jurídica simples ou complexa, implícita ou explícita, barata ou cara, com maior ou menor tolerância aos riscos do negócio, com contratos diretos ou terceirizados, com maior ou menor carga tributária etc.

De qualquer maneira, é fundamental observar que a definição precisa da Proposta de Valor (tal como a definição dos Segmentos de Clientes) é absolutamente fundamental para o sucesso de qualquer negócio. Por isso, a empresa deve considerar sempre, seriamente, a possibilidade de testar as Propostas de Valor definidas teoricamente no Canvas com os seus Segmentos de Clientes, preferencialmente antes da implementação efetiva das mesmas. E isso pode ser feito, quer por meio de pesquisas de mercado (qualitativas e quantitativas), 
quer por meio de Grupos Focais com parcelas significativas dos Segmentos de Clientes, quer por meio de protótipos, ou pela utilização de um conjunto de análises críticas e estratégicas que permitam minimizar as possibilidades de insucesso do negócio proposto ou já existente.

\subsection{Canais}

A elaboração do Quadro Modelo de Negócios ou Canvas pressupóe também a definição acerca dos canais por meio dos quais a empresa ou negócio alcança os seus Segmentos de Clientes para entregar as Propostas de Valor estabelecidas. É preciso, portanto, definir os canais de comunicação, de distribuição e de vendas dos produtos e/ou serviços da empresa. Para isso, deve-se considerar todos os pontos de contato da empresa com os seus clientes, por meio dos quais eles conhecem os produtos/serviços, avaliam as propostas de valor relativas aos mesmos, adquirem os produtos/serviços e também recebem suporte e assistência técnica. Nesse sentido, então, os Canais não são constituídos apenas pelos locais - físicos ou digitais - por meio dos quais os clientes compram, mas também nos quais os clientes conhecem, avaliam, compram, recebem, reclamam (são as seguintes, então, as fases do canal: conhecimento, avaliação, compra, entrega, pós-venda).

Como OSTERWALDER e PIGNEUR demonstram (2013, p. 27), os Canais podem ser diretos (equipes de vendas, site) ou indiretos (loja para revenda operadas pela organização ou por terceiros - por meio de franquias, por exemplo), próprios (lojas próprias), terceirizados (lojas de parceiros, atacadistas, sites de terceiros, distribuidores ou concessionários), ou uma mistura de todos os tipos. Todavia, o sucesso de qualquer negócio depende muito do mix de Canais escolhidos e usados para satisfazer o modo como os diversos Segmentos de Clientes serão contatados. Nesse sentido, os mencionados autores afirmam, que:

Os canais de parceria levam à margens de lucro menores, mas permitem que uma organizaçáo expanda seu alcance e se beneficie da força do parceiro. Canais particulares têm margens de lucro maiores, mas podem custar dinheiro para preparar e operar. O truque é encontrar o equilíbrio entre os diferentes tipos de canais, a fim de integrá-los de modo a criar uma ótima experiência para o consumidor e maximizar os lucros. (2013, p. 27)

Não obstante, o sucesso de qualquer negócio pressupõe não apenas a definição formal dos Canais no Quadro Modelo de Negócios, mas a gestão eficiente e sistemática do funcionamento de todos eles. Assim, como em quase todos os negócios, de maneira direta ou indireta, são estabelecidas relaçóes da empresa com pessoas naturais (seres humanos), a gestão eficiente dos Canais exige a identificação de todos eles, bem como o design e/ou 
redesign desses Canais para que a relação do negócio com os seus clientes seja cada vez mais humanizada, customizada, emocional e, por conta disso tudo, mais vinculante, mais afetiva. Essa gestão acaba sendo muito importante não apenas para conquistar, mas para reter e multiplicar clientes, o que quase sempre determina a sustentabilidade e o sucesso do negócio.

Do ponto de vista da estruturação jurídica do negócio ou da empresa, imediatamente após a identificação dos Canais por meio dos quais a empresa entra ou vai entrar em contato com os Segmentos de Clientes para entrega das Propostas de Valor, é absolutamente fundamental estabelecer um modelo de governança voltado para a regulação das relações internas entre os empregados e prestadores de serviços da empresa, bem como a normalização da relação desta com os seus diversos clientes. Por meio desse modelo de governança devem também ser estabelecidas as regras infra-legais e internas de conduta das pessoas que irão entrar em contato com os clientes em nome da empresa, bem como a estrutura dos modelos de contratos que irão reger o relacionamento da clientela com a empresa, tais como, dentre outros, contratos de compra e venda, e de prestação de serviços, nos quais devem ser estabelecidas todas as condiçôes inerentes ao negócio proposto, tais como: objeto, preço, prazo, garantias, política de trocas, meios extrajudiciais para solução de eventuais problemas etc.

\subsection{Relacionamento com Clientes}

Nos tempos atuais, mais do que nunca, a experiência do cliente constitui um elemento fundamental para o sucesso de qualquer negócio ou empresa. Por isso, na elaboração do modelo teórico de qualquer negócio, a definição dos tipos de relação que a empresa tem ou terá com os seus diversos clientes é um fator crítico de sucesso. Nesse sentido, o relacionamento com os clientes deve ser motivado pela conquista e/ou pela retenção dos clientes, ou pela ampliação das vendas (OSTERWALDER e PIGNEUR, 2013, p. 28).

Para a elaboração do Quadro Modelo de Negócios, faz-se necessário, portanto, a resposta a algumas indagaçóes, tais como, por exemplo, as seguintes: (i) que tipo de relacionamento os clientes esperam? (ii) que tipos de relacionamentos a empresa ou negócio já estabelece com os seus clientes? (iii) como tipos de relacionamentos pretendidos ou estabelecidos se conectam e se integram com o restante da empresa?

De qualquer maneira, como OSTERWALDER e PIGNEUR demonstram (2013, p. 29), os relacionamentos com os clientes podem ser estabelecidos: (i) por meio de assistência pessoal e direta, baseada na interação humana; (ii) por meio de assistência pessoal dedicada, com o destacamento de uma pessoa para o atendimento específico, direto e profundo do cliente; (iii) por meio do sistema de autoatendimento (self-service), que determina um relacionamento indireto do negócio ou empresa com os clientes; (iv) por 
meio de serviços automatizados, com um sistema mais sofisticado de self-service personalizado de acordo com o perfil específico do cliente; (v) por meio de comunidades online de usuários, instituídas pela própria empresa para permitir e/ou facilitar a troca de conhecimentos e de experiências entre os clientes; (vi) por meio do sistema de cocriação, por meio do qual a empresa convida os seus clientes a cocriarem as propostas de valor e os próprios produtos/serviços que lhes são oferecidos (é o que ocorre, por exemplo, com o You Tube, no qual o conteúdo é cocriado pela empresa e pelos usuários).

De qualquer maneira, a definição do relacionamento com os clientes também determina a definição de um ou de alguns modelos jurídicos específicos, com diversos desdobramentos, que dependem de o relacionamento ser pessoal e direto, dedicado, realizado por meio de sistema de autoatendimento ou self-service, automatizado etc.

\subsection{Fontes de Receita}

A sustentabilidade de qualquer negócio ou ideia depende, quase sempre, das fontes de receitas necessárias para o pagamento dos custos e para a geração de superávit.

Nesse sentido, como OSTERWALDER e PIGNEUR esclarecem (2013, p. 30), um Modelo de Negócios pode envolver, basicamente, dois tipos de Fontes de Receitas: (i) as receitas provenientes de um pagamento único; (ii) as rendas recorrentes. Por outro lado, independentemente dos tipos das Fontes de Receitas, os preços podem ser fixos, predefinidos em listas, fixados a partir de características do produto/serviço, dependente dos tipos ou características dos segmentos de clientes, ou, ainda, dependente do volume ou da quantidade comprada. Já os preços dinâmicos mudam de acordo com as variaçóes e condiçóes de mercado e/ou do momento de compra, com fundamento na variação da oferta e da demanda, bem como dependem de competiçáo e/ou do poder e das habilidades de negociação,

De qualquer maneira, a análise estratégica das Fontes de Receitas para a composição do Quadro Modelo de Negócios pressupóe indagar sobre quais valores os clientes estão realmente dispostos a pagar, bem como sobre os valores efetivamente pagos na atualidade pelos clientes, mas, também, sobre a forma de pagamento e sobre o percentual de contribuição de cada uma das fontes de receitas para a sustentação do negócio.

São diversas as fontes possíveis de receitas para qualquer empresa ou negócio, tais como, por exemplo: (i) venda de recursos; (ii) taxa de uso; (iii) taxa de assinatura; (iv) empréstimo; (v) aluguel; (vi) leasing; (vii) licenciamento; (viii) corretagem; (ix) anúncio; (x) patrocínio; (xi) doação.

Inquestionavelmente, cada uma desses tipos ou espécies de Fontes de Receitas pressupóe também um nível diferente de organização administrativa, comercial, financeira e, sobretudo, jurídica do negócio e da empresa. 


\subsection{Recursos Principais}

O funcionamento de qualquer negócio ou empresa pressupóe identificar quais são os recursos principais para que as propostas de valor estabelecidas sejam entregues, com eficiência e eficácia, aos diversos segmentos de clientes. Nesse sentido, cada modelo de negócio requer específicos tipos de Recursos Principais, que podem ser físicos, financeiros, intelectuais, humanos, e podem ser próprios, alugados ou adquiridos de parceiros-chave (OSTERWALDER e PIGNEUR, 2013, p. 34).

\subsection{Atividades-Chave}

Como OSTERWALDER e PIGNEUR esclarecem:

Todo Modelo de Negócios pede por um número de Atividades-Chave. São as açóes mais importantes que uma empresa deve executar para operar com sucesso. Assim como os Recursos Principais, elas são necessárias para criar e oferecer a Proposta de Valor, alcançar mercados, manter Relacionamento com o Cliente e gerar renda. E, assim como os Recursos Principais, as Atividades-Chave se diferenciam dependendo do tipo de Modelo de Negócios. (2013, p. 36)

Dessa maneira, basicamente, as atividades-chave são aquelas que a própria empresa deve executar diretamente para que a proposta de valor seja entregue adequadamente aos diversos segmentos de clientes, com o máximo aproveitamento possível.

Algumas atividades-chave são de produção e relacionadas com a fabricação e entrega de produtos e serviços aos segmentos de clientes, nas quantidades e qualidades necessárias para o sucesso do negócio. Por outro lado, outras atividades-chave relacionam-se com a solução de problemas de clientes específicos, em modelos de negócios que normalmente exigem o gerenciamento de conhecimento e de treinamento contínuo, como é o caso dos serviços de consultoria e de prestação de serviços de uma maneira geral. Finalmente, existem atividades-chave que decorrem de modelos de negócios projetados com atividadeschave estabelecidas por meio de uma plataforma (um site, um software, um aplicativo) ou de uma rede (OSTERWALDER e PIGNEUR, 2013, p. 37).

Do ponto de vista do Direito Empresarial Societário, normalmente as atividadeschave são exatamente aquelas estabelecidas na cláusula que define o objeto social e, portanto, a finalidade da sociedade empresária que estrutura a empresa. E, no âmbito do Direito do Trabalho, são exatamente essas atividades-chave da empresa que, no Brasil, não podem ser, em princípio, terceirizadas, em virtude do disposto na Súmula n. 331 do Tribunal Superior do Trabalho, que prevê o seguinte: 
CONTRATO DE PRESTAÇÃO DE SERVIÇOS. LEGALIDADE (nova redaçáo do item IV e inseridos os itens V e VI à redaçáo) - Res. 174/2011, DEJT divulgado em 27, 30 e 31.05.2011

I - A contratação de trabalhadores por empresa interposta é ilegal, formando-se o vínculo diretamente com o tomador dos serviços, salvo no caso de trabalho temporário (Lei no 6.019, de 03.01.1974).

II - A contratação irregular de trabalhador, mediante empresa interposta, não gera vínculo de emprego com os órgãos da Administração Pública direta, indireta ou fundacional (art. 37, II, da CF/1988).

III - Não forma vínculo de emprego com o tomador a contratação de serviços de vigilância (Lei no 7.102, de 20.06.1983) e de conservação e limpeza, bem como a de serviços especializados ligados à atividade-meio do tomador, desde que inexistente a pessoalidade e a subordinaçấo direta.

IV - O inadimplemento das obrigaçôes trabalhistas, por parte do empregador, implica a responsabilidade subsidiária do tomador dos serviços quanto àquelas obrigaçóes, desde que haja participado da relação processual e conste também do título executivo judicial.

V - Os entes integrantes da Administração Pública direta e indireta respondem subsidiariamente, nas mesmas condições do item IV, caso evidenciada a sua conduta culposa no cumprimento das obrigaçóes da Lei n. ${ }^{\circ}$ 8.666, de 21.06.1993, especialmente na fiscalização do cumprimento das obrigaçóes contratuais e legais da prestadora de serviço como empregadora. A aludida responsabilidade não decorre de mero inadimplemento das obrigaçóes trabalhistas assumidas pela empresa regularmente contratada.

VI - A responsabilidade subsidiária do tomador de serviços abrange todas as verbas decorrentes da condenação referentes ao período da prestação laboral. ${ }^{1}$

\subsection{Parcerias Principais}

Da mesma maneira como nenhum ser humano é uma ilha, todas as empresas e negócios dependem sempre de uma rede constituída por fornecedores, parceiros e clientes. Por isso, a definição de um Modelo de Negócios pressupóe a descrição da rede de fornecedores e de parceiros que colocam o negócio para funcionar de maneira eficiente.

Segundo OSTERWALDER e PIGNEUR, existem quatro tipos diferentes de parcerias:

1 http://www3.tst.jus.br/jurisprudencia/Sumulas_com_indice/Sumulas_Ind_301_350.html\#SUM-331, acesso em 17 de Fevereiro de 2015. 
1. Alianças estratégicas entre nâo competidores;

2. Competição: parcerias estratégicas entre concorrentes;

3. Joint ventures para desenvolver novos negócios;

4. Relação comprador-fornecedor para garantir suprimentos confiáveis. (2013, p. 38)

E, segundo os mesmos autores, as motivaçóes para uma parceria podem ser: (i) a otimização e a busca de economia de escala, já que é irracional a empresa executar absolutamente todas as atividades necessárias à sua existência e desenvolvimento; (ii) a redução de riscos e incertezas, já que as alianças estratégicas acabam promovendo a divisão e a mitigação dos riscos inerentes ao negócio; (iii) a aquisição de recursos e atividades particulares de terceiros, já que muito poucas empresas possuem todos os recursos (financeiros, humanos, tecnológicos etc) ou executam direta e pessoalmente todas as atividades descritas em seus modelos de negócios.

Logicamente, não há como estabelecer parcerias sem uma estrutura jurídica adequada à eficácia plena dos objetivos propostos ou planejados. E essa estrutura jurídica, geralmente de ordem obrigacional, pode ser estabelecida, dependendo do caso concreto, de maneira formal ou informal, explícita ou implícita, expressa ou tácita.

\subsection{Estrutura de Custo}

Não existe milagre. A geração de receita e de lucro, bem como a manutenção e/ou aprimoramento do relacionamento com os diversos segmentos de clientes pressupóe uma estrutura de custo compatível com o tamanho e com a complexidade do negócio ou da empresa. Por isso, a construção ou descrição de um Modelo de Negócios exige também a identificação de todos os principais custos financeiros e não financeiros exigidos para o perfeito desenvolvimento da empresa.

Especificamente para a montagem do Quadro Modelo de Negócios, a composição do campo relativo à estrutura de custo requer a resposta às indagaçóes sobre os custos mais importantes do modelo de negócios, sobre os recursos principais e atividades-chave que são mais caros.

Todavia, vale sempre observar que alguns modelos de negócios são orientados pelo baixo custo e outros pelo valor agregado e oferecido ao cliente por meio de um ou de vários produtos e/ou serviços. Nesse sentido, nos modelos de negócios direcionados pelo custo os esforços e a estrutura organizacional do negócio procura minimizar o custo sempre que possível, o que geralmente ocorre por meio de automação máxima e diversas terceirizaçōes. Por outro lado, nos negócios direcionados pelo Valor, a preocupação com os custos é menor, já que o mais importante é atender às expectativas 
dos diversos segmentos de clientes, como acontece, por exemplo, no segmento dos serviços de luxo.

De qualquer maneira, segundo OSTERWALDER e PIGNEUR, as estruturas de custos podem ter como características os custos fixos (que não variam em virtude do volume dos produtos ou serviços oferecidos aos clientes), os custos variáveis (que se modificam na proporção do volume dos artigos ou serviços produzidos), a economia de escala (com vantagens decorrentes do aumento da demanda pelo produto ou serviço oferecido aos clientes), a economia de escopo (quanto maior o escopo, maior as vantagens auferidas pelo negócio ou empresa) (OSTERWALDER e PIGNEUR, 2013, p. 41).

Independentemente dos tipos ou das características da estrutura de custos, a estratégia jurídica utilizada é fundamental para reforçar a lógica do baixo custo, ou da proposta de valor. Nesse sentido, especialmente em relação à estratégia de baixo custo, a adequada estruturação jurídico-tributária constitui um elemento fundamental para o controle dos custos tributários do negócio, considerando-se, sobretudo, a miríade tributária na qual todos os negócios realizados no Brasil estão envolvidos.

\section{Análise Estratégica do Direito}

No Brasil, especialmente, o Direito ainda é fundamentalmente reconhecido como uma ciência normativa, voltada principalmente para a prevenção ou para a solução judicial de conflitos decorrentes de casos ocorridos no passado. Por isso, a cultura jurídica brasileira é marcada excessivamente pelo pressuposto do conflito, do processo judicial e pelo paradigma quase absoluto do uso de uma única ou de uma principal fonte do direito: a lei.

Contudo, a cultura jurídica brasileira, especialmente em matéria de direito empresarial ou mercantil, precisa avançar para atender aos anseios da sociedade contemporânea, sobretudo no âmbito de atuação das organizações empresariais. E isso pressupóe reconhecer a necessidade de inovação e de uso do Direito como instrumento de realização dos objetivos estratégicos das organizaçôes empresariais privadas e públicas.

A construção de uma cultura jurídica nova e concatenada com as necessidades do mercado e da empresa pressupóe, primeiro, a mudança do modelo mental dominante, que implica a modificação do modo de pensar, de ensinar e, principalmente, de vivenciar a prática do Direito.

A grande dificuldade na imposição das mudanças necessárias à construção da cultura jurídica determinada pelas necessidades do mercado é que o brasileiro, culturalmente, é 
geralmente refratário ao planejamento estruturado de suas açôes. As empresas são organizaçóes dos meios de produção, dirigidas, na prática, por pessoas. Por isso, em qualquer lugar, a empresa influencia as pessoas e as comunidades nas quais ela atua, mas também é muito influenciada pela cultura das pessoas que a faz existir. Por isso, em regra, as empresas brasileiras, especialmente as pequenas e médias, sofrem as consequências da deficiência de planejamento, própria da cultura de parte significativa dos brasileiros. E isso pode ser observado pelo número significativo de negócios que começam e são finalizados no curto espaço de tempo no Brasil, geralmente em virtude da falta de planejamento administrativo, financeiro, comercial, jurídico.

Nesse sentido, é importante observar, que:

Planejar é, em síntese, construir cenários possíveis, com objetivo de antever ou antecipar o futuro, para a concretização dos objetivos estabelecidos antes. Nesse sentido, o planejamento implica a elaboração de um conjunto de ações voltadas para implementação dos objetivos pré-determinados. (GABRICH, 2012, p. 34/35)

No âmbito da ciência do Direito, é importante também reconhecer a finalidade do planejamento jurídico e da análise estratégica do Direito, pois:

[...] o Direito deve ser compreendido como instrumento de estruturação dos objetivos das pessoas (naturais e jurídicas, de Direito Público ou de Direito Privado), para que estes sejam alcançados com o máximo possível de aproveitamento (de tempo, de conforto psicológico e até de dinheiro), de maneira a determinar o máximo de eficiência e de felicidade possível às pessoas. Para a imposição da análise estratégica do Direito, faz-se também necessário desenvolver a metodologia de análise jurídica baseada nos objetivos propostos pelas pessoas, e não mais nos casos - sobretudo conflituosos - do passado. Isso implica reconhecer o Direito como um conjunto de alternativas - jurídicas - para a estruturação dos objetivos das pessoas, fundamentalmente sem conflito e sem processo judicial, especialmente por meio da conciliação, da mediação e da arbitragem. Nessa dimensão, o Direito não mais pode ser encarado apenas como um conjunto de normas legais postas no ordenamento jurídico para permitir a "soluçáo" de conflitos, fundamentalmente por meio de processos judiciais, com a obrigatória participação do Estado, por meio do Poder Judiciário. (GABRICH, 2012, p. 75/76)

Ocorre que, no âmbito das organizaçóes (privadas e públicas), a análise estratégica do Direito exige que o jurista, antes de desenvolvê-la, realize um diagnóstico ou um briefing para o perfeito entendimento dos problemas, dos interesses, dos desejos, das necessidades das pessoas (naturais e jurídicas) envolvidas com o negócio, com a empresa, com 
a organização. Além disso, é necessária a perfeita compreensão pelo jurista da estrutura de custos e de receitas do negócio, bem como as atividades chave, as parcerias principais, além dos canais de relacionamento com a clientela. Em síntese, é fundamental o conhecimento perfeito do modelo de negócio adotado pela empresa, bem como do planejamento estratégico estabelecido para a sua implementação e gestão. Sem isso, há sério risco de um total descompasso entre o negócio, sua gestão e a estratégia jurídica escolhida para a sua realização mais eficiente possível.

Daí, então, a importância da concatenação do Canvas ou Quadro Modelo de Negócios, com um Quadro Jurídico de Negócios que possa ser estabelecido e usado também estrategicamente, para que sejam construídas estruturas jurídicas que serão efetivadas para organizar e/ou para maximizar as ideias e os negócios previstos no Canvas.

\section{Quadro do Modelo Jurídico de Negócios}

De fato, como foi mencionado antes, não existe ideia, negócio ou empresa, de controle privado ou público, que não exija uma adequada estratégia jurídica para ser implementada(o) com a máxima eficiência possível. Da mesma maneira como é importante estabelecer um Modelo de Negócios inteligível, visual e prático para a construção dos planos de negócios e dos planos de ação necessários ao desenvolvimento da atividade econômica correspondente, é fundamental a construção de um quadro que demonstre o Modelo Jurídico do Negócio, com as mesmas características do Canvas (simplicidade, completude, fácil entendimento, comunicação visual etc), para que seja estabelecida uma estratégia jurídica geral que permita a realização do negócio proposto com a máxima eficiência possível, com o melhor aproveitamento do tempo, das pessoas e dos recursos financeiros disponíveis em um dado momento.

A exemplo do Quadro Modelo de Negócios (Canvas) proposto por OSTERWALDER e PIGNEUR, o Quadro Modelo Jurídico de Negócios também pode ser divido em nove campos, visualmente representados em uma única tela, para estabelecer, de maneira clara, objetiva e direta, a macroestrutura jurídica de qualquer ideia ou negócio representado em um Canvas. Nesse sentido, são pelo menos nove estratégias jurídicas para organização adequada de qualquer ideia ou negócio, com destaque para: (i) estrutura jurídica e/ou societária; (ii) relacionamento com os clientes e com o mercado; (iii) distribuição e logística; (iv) colaboradores; (v) fornecedores e parceiros; (vi) financiamento; (vii) estratégia tributária municipal; (viii) estratégia tributária estadual; (ix) estratégia tributária federal.

Do ponto de vista de comunicação e estrutura imagética, o quadro Modelo Jurídico de Negócios pode ser, então, assim representado: 


\section{Canvas • Modelo Jurídico de .}

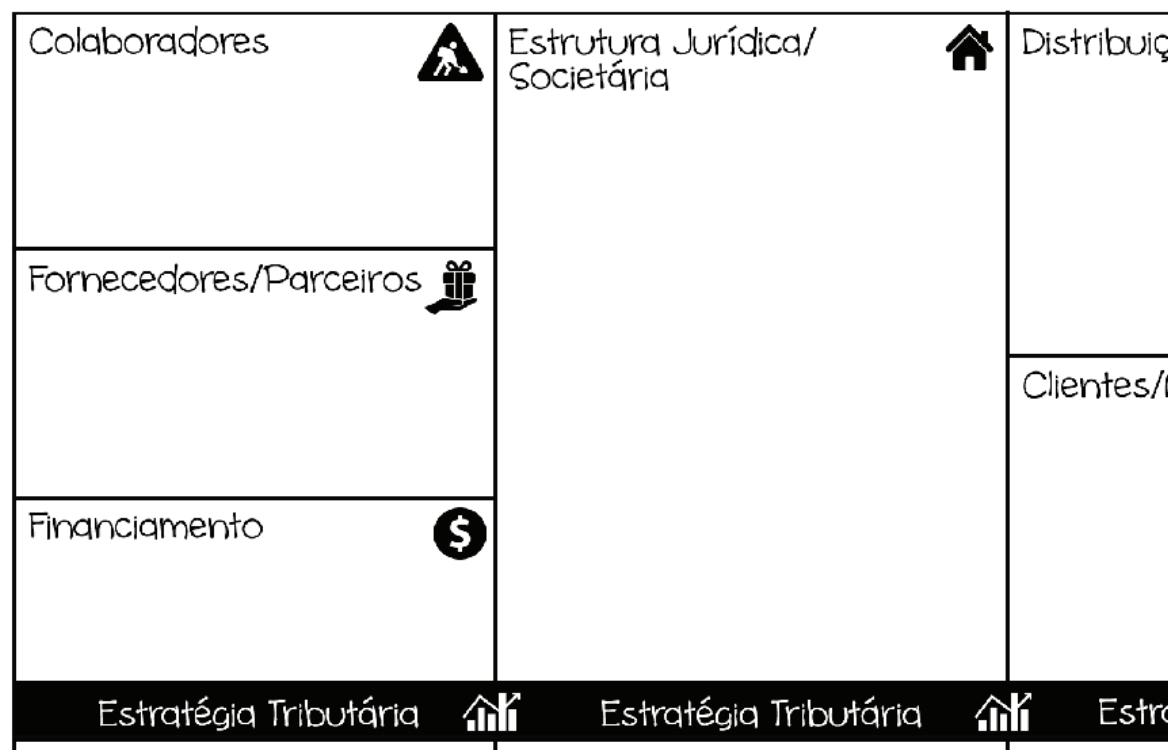

\subsection{Estrutura Jurídica e Societária}

O desenvolvimento de qualquer negócio exige, antes de tudo, a definição da estrutura jurídica e/ou societária que será usada pelas pessoas que pretendem empreender.

Ao contrário do que muitas vezes acontece na prática, a definição da estratégia jurídico-societária pressupóe o perfeito conhecimento acerca do negócio que será desenvolvido, dos segmentos de clientes que serão atendidos, das propostas de valor que serão entregues aos clientes, os canais e os tipos de relacionamento que serão estabelecidos com os clientes, as fontes de receitas (no curto, médio e longo prazos), os recursos principais, os principais parceiros, a estrutura de custos (no curto, médio e longo prazos). Ou seja, antes de tudo, é preciso conhecer e entender o Modelo do Negócio.

Mas é necessário ir além do Quadro Modelo de Negócios. É preciso conhecer também o Plano de Negócios, o Planejamento Estratégico (Premissas - valor, visão, missão -, Objetivos, Metas, Indicadores de desempenho, Concorrência, Planos de Ação), e o perfil psicológico e profissional dos sócios (controladores e minoritários).

Em relação à essa última análise, relativa ao modelo mental dos sócios, especialmente nas empresas de perfil familiar e/ou que possam ser classificadas como sociedades de 
pessoas, é fundamental que o estrategista jurídico conheça detalhadamente os sócios e também as suas famílias, a história de vida de cada um, os seus sonhos e projetos futuros, o estado civil e o perfil sócio-econômico-cultural dos sócios e de suas famílias, bem como o apetite ao risco que esses sócios estão dispostos a assumir, além do interesse (ou não) dos sócios (e de seus familiares) de participarem (direta ou indiretamente) da gestão dos negócios etc.

Apesar de todos esses fatores muitas vezes não serem considerados para a definição da estrutura jurídico-societária inicial do negócio, essa análise se mostra fundamental, especialmente nos pequenos e médios negócios, de caráter essencialmente personalista e familiar. Todavia, a mesma análise estratégica deve ser realizada quando se trata de um negócio de caráter capitalista, ou mesmo de um negócio ou objetivo que será desenvolvido por uma instituição (organização) pública ou privada. E isso se justifica porque, em última instância, qualquer atividade econômica organizada (empresa, no sentido econômico e amplo do termo), direta ou indiretamente, acaba sendo realizada por (ou para) uma ou várias pessoas naturais.

De fato, o sucesso do negócio depende muito do reconhecimento dessas informaçóes para que a estrutura jurídico-societária seja estabelecida por meio das diversas possibilidades previstas no ordenamento jurídico brasileiro, tais como, dentre outras: empresário individual (com ou sem registro na Junta Comercial), empresa individual de responsabilidade limitada (EIRELI), sociedade em comum, sociedade em conta de participação, sociedade em nome coletivo, sociedade em comandita simples, sociedade limitada, sociedade anônima, sociedade em comandita por açóes, sociedade simples, sociedade cooperativa, associação, organização religiosa, partido político, fundação. Além disso, essa análise permite que o estrategista jurídico determine qual será a estrutura de administração do negócio, como, por exemplo, a definição da existência (ou não) de diretoria, conselho de administração, conselho fiscal, delegação de poderes de gestáo, manual de governança corporativa (que garanta respeito à hierarquia organizacional, ao orçamento, bem como aos limites de decisão e de alçada) etc.

\subsection{Relacionamento com Clientes/Mercado}

Da mesma maneira como é importante a definição prévia da estrutura jurídico-societária que irá sustentar o negócio, é fundamental a definição prévia dos instrumentos jurídicos que devem ser desenvolvidos para a devida sustentação de todos os pontos de relacionamento do negócio e da empresa, com os seus clientes, com os stakeholders e com o mercado.

Nesse sentido, como, na maioria dos casos, o relacionamento da empresa com os clientes é transacional e obrigacional, faz-se necessária a definição dos tipos de contratos 
que serão usados para organização dessas relações e que deverão ser elaborados posteriormente à elaboração do Quadro Jurídico de Negócios (mas antes do início da operação), tais como, dentre outros: contrato de compra e venda, contrato de prestação de serviços, termos e políticas de responsabilidade, termos e políticas de garantia e de troca, contratos de financiamento, procuraçóes etc.

\subsection{Distribuição e Logística}

Especialmente nas empresas que atuam nos setores da indústria e do varejo, mas também naquelas que atuam no setor de serviços, garantir a eficiência da distribuição e da logística é, muitas vezes, a chave do sucesso do empreendimento.

Para que isso aconteça sem rupturas que causem impacto negativo no negócio é muito importante a construção, a manutenção e o desenvolvimento de uma rede de transporte e de distribuição. Normalmente, a importância do perfeito funcionamento dessa rede de distribuição e de logística somente se mostra relevante para o negócio, quando ela não funciona. Mas, para que as falhas não aconteçam ou sejam minimizadas, é crucial a utilização estratégica de diversos tipos de contratos, que devem ser (primeiro) idealizados e descritos no Quadro Jurídico de Negócios e (depois) prototipados e testados por meio de minutas e/ou de precontatos. Dentre tais contratos, destacam-se, geralmente, dentre outros, os seguintes: distribuição, transporte, armazenagem, afretamento, locação, franquia empresarial, representação comercial etc.

\subsection{Colaboradores}

Apesar das mudanças significativas nos tipos e nas formas das relaçóes de trabalho e da crescente automatizaçáo dos negócios que vêm ocorrendo nas últimas décadas, a empresa (ainda) náo pode prescindir do trabalho de um número importante de pessoas naturais. As relaçóes jurídicas que sustentam o trabalho continuam sendo normalmente muito importantes não apenas para a estruturação e para o sucesso dos negócios, mas também para a estruturação da vida pessoal e familiar dos colaboradores da empresa.

As relaçóes de trabalho na empresa mudaram muito (e continuam mudando) desde a Revolução Industrial e do surgimento do Direito do Trabalho. Os paradigmas da produção em massa, da padronização do trabalho em linhas de montagem, da subordinação, da venda do tempo pelo trabalhador, da remuneração exclusivamente em dinheiro, da especialização máxima, da definição rígida de cargos e de funções, do controle e da limitação de liberdade do trabalhador etc, estão sendo substituídos, cada dia mais, pelos novos paradigmas do trabalho, tais como: colaboração e cocriação de valor, voluntariado, ausência de hierarquia e/ou de subordinação, redução e/ou eliminação dos cargos 
(holocracia), ampliação das funções, trabalho organizado por projetos e orientado por objetivos e metas, trabalho à distância, ausência de controle de jornada, liberdade de acesso às informaçóes do negócio, remuneração baseada na conjunção entre dinheiro, qualidade de vida e reconhecimento.

Essa situação fática representa um grande desafio para o estrategista jurídico da empresa contemporânea, especialmente no Brasil, pois, neste país, a lógica do Direito do Trabalho e dos órgãos de fiscalização e de controle do trabalho na empresa ainda está atrelada aos paradigmas do passado, patrimonialista e industrial.

Assim, no campo destinado à estruturação jurídica dos vínculos existentes entre o negócio e os seus colaboradores, faz-se necessária a descrição das diversas possibilidades atuais, tais como, dentre outras: contratos de trabalho; plano de cargos, salários e responsabilidades; plano de premiação; políticas de participação nos lucros e resultados; código de ética profissional; políticas de governança corporativa; programas de integridade e compliance; acordo coletivo de trabalho; termo de compensação de horas; contrato de voluntariado; contrato de associação profissional; usufruto temporário, condicional e oneroso de quotas ou de açóes.

\subsection{Fornecedores e Parceiros}

A estruturação de qualquer negócio exige a construção e o desenvolvimento de uma rede sólida de fornecedores e de parceiros.

Em todas as empresas, os fornecedores são tão importantes quanto os clientes e, por isso, esse relacionamento (obrigacional) deve ser sempre muito bem estruturado, quer do ponto de vista negocial, quer do ponto de vista psicológico e/ou jurídico.

Para que o relacionamento com os fornecedores e demais parceiros da cadeia produtiva aconteça, just in time, sem rupturas e sem a necessidade da manutenção e do controle de grandes estoques (que implicam normalmente custos financeiros significativos para muitos negócios), é muito importante a construção, a manutenção e o desenvolvimento de uma rede de fornecedores e distribuidores. Qualquer falha no sistema de fornecimento pode ser fatal para um negócio.

Assim, vários contratos e estratégias jurídicas podem ser explicitadas no Quadro Jurídico de Negócios, tais como, exemplificativamente: contrato de fornecimento, contrato de franquia empresarial, contrato de associaçáo para manutenção de uma rede de compras, contrato de transporte etc.

\subsection{Financiamento}

As linhas e os meios de financiamento quase sempre são absolutamente fundamentais para a estruturação dos negócios. 
Sendo assim, cabe também ao estrategista jurídico, considerando a rentabilidade média e as necessidades e os custos do capital estabelecidos para o negócio, construir um arcabouço jurídico que permita a perfeita fruição das engrenagens financeiras do negócio e da empresa.

Especialmente nos grandes empreendimentos, nos quais é fundamental a alocação de gigantescos volumes de capital, é necessária a elaboração de uma estratégia jurídica e financeira que permita não apenas o acesso ao capital, mas que este seja remunerado e pago pelos resultados gerados pelo próprio negócio (Project Finance).

Daí a importância da descrição dos principais atos jurídicos que serão desenvolvidos para a sustentação financeira do negócio proposto, tais como: emissão de valores mobiliários e/ou outros títulos de crédito; cartôes de crédito e débito; contratos de empréstimo; financiamento, locação; permuta; leasing; factoring; políticas de financiamento direto de clientes, dentre outros.

\subsection{Estratégias Tributárias: Municipal, Estadual, Federal}

Especialmente no Brasil, um dos mais importantes custos diretos dos negócios é constituído pela carga tributária.

Uma intrincada teia de tributos (impostos, taxas, contribuiçóes fiscais e parafiscais) e de obrigaçôes acessórias afeta significativamente todos os negócios no Brasil.

Nada mais natural, então, do que o Quadro Jurídico de Negócios conter espaços destinados à descrição das obrigações tributárias incidentes sobre o negócio da empresa, em todos os níveis e fases da operação. Cabe, assim, a descrição dos tributos municipais, estaduais, federais incidentes sobre o negócio proposto, bem como dos regimes de tributação, apuração e pagamento, além da classificação tarifária de produtos e serviços, bem como das respectivas alíquotas e obrigaçóes acessórias.

É importante observar, todavia, que, dependendo do país no qual o negócio esteja inserido, o campo relativo às estratégias tributárias pode ser mais reduzido ou ampliado, na mesma proporção da complexidade ou da simplicidade do sistema tributário aplicável à espécie.

\section{Conclusões}

O Direito Empresarial não tem existência científica ou prática autônoma. O Direito Empresarial não é apenas o direito da empresa e dos empresários. O Direito Empresarial é o direito na empresa. Assim, sem a empresa, não há Direito Empresarial.

Nos tempos atuais, a empresa é totalmente organizada de acordo com a lógica do planejamento e da gestão estratégica. Por isso, estabelecer objetivos e metas, identificar 
responsabilidades, evidenciar e monitorar indicadores de desempenho, garantir em todas as etapas a maior eficiência geral possível, faz parte do dia-a-dia de qualquer negócio ou organização, no Brasil e em todos os demais países.

Ocorre que a lógica de planejamento precede a própria existência da empresa. A construção de um modelo de negócios é ponto de partida fundamental para os novos empreendimentos, mas também ponto de transformação e de sustentabilidade dos já existentes. Conhecer em sua completude o modelo do negócio é um elemento muito importante para a construção de uma ou de várias estratégias que garantam a maior eficiência possível da empresa.

Por isso, OSTERWALDER e PIGNEUR (2013) desenvolveram Business Model Generation, por meio do Canvas ou o Quadro Modelo de Negócios, que vem sendo usado, cada vez mais, para a construção e/ou para a evolução estratégica de diversos tipos, modelos e tamanhos de negócios e empresas. A grande virtude do Canvas é permitir, de maneira simples (mas não simplificada), a ideação, o pensamento, a reflexão e a visualização do modelo completo do negócio, o que acaba favorecendo o processo de inovação estratégica nas organizaçôes (privadas e públicas). Daí o seu sucesso.

Todavia, como todos os negócios, empresas e organizaçóes precisam de uma ou de várias estratégias jurídicas para o seu desenvolvimento, nada mais natural do que a construção de um Quadro Jurídico de Negócios, com a mesma lógica de simplicidade e de completude do Canvas proposto por OSTERWALDER e PIGNEUR, e que deve ser usado em conjunto com aquele, para a perfeita estruturação jurídica do modelo do negócio, em qualquer empresa ou organização (pública ou privada).

\section{Referências}

BERNARDI, Luiz Antonio. Manual de Plano de Negócios: fundamentos processos e estruturação. São Paulo: Atlas, 2011.

HITT, Michael. IRELAND, Duane. HOSKISSON, Robert. Administração estratégica: competitividade e globalização. São Paulo: Cengage Learning, 2011.

GABRICH, Frederico de Andrade. Análise Estratégica do Direito. Belo Horizonte: Universidade Fumec, 2010.

GABRICH, Frederico de Andrade. Inovação no Direito. Belo Horizonte: Universidade Fumec, 2012.

LOBATO, David Menezes. MOYSÉS FILHO, Jamil. TORRES, Maria Cândida Sotelino. RODRIGUES, Murilo Ramos Alambert. Estratégia de empresas. 6a edição, Rio de Janeiro: editora FGV, 2005. 
NOGUEIRA, Carla Rossana de Araujo Torres. ALMEIDA, Marcia Rejane de Araujo. Plano de Negócios e Planejamento Estratégico: Ferramentas que geram vantagem competitiva. Uma abordagem sobre o BSC enquanto ferramenta estratégica aplicada à Escola do Design. Tese apresentada no VIII Convibra Administração - Congresso Virtual Brasileiro de Administração - www.convibra.com.br, 09/11/2011, <http://www.convibra.com.br/upload/paper/adm/adm_2710.pdf >, acesso em $13 / 12 / 2014$.

BIAGIO, Luiz Arnaldo; BATOCCHIO Antônio. Plano de negócios: estratégia para micro e pequenas empresas. São Paulo: Manole, 2012.

OSTERWALDER, Alexander; PIGNEUR, Yves. Inovação em Modelos de Negócios: um manual para visionários, inovadores e revolucionários. Rio de Janeiro: Alta Books, $6^{\mathrm{a}}$ reimpressão, 2013.

PORTER, Michael E.. Estratégia Competitiva: técnicas para análise de indústrias e da concorrência. Rio de Janeiro: Elsevier, 7ª edição - 29ª reimpressão, 1986.

WILDAUER, Egon Walter. Plano de Negócios: elementos constitutivos e processo de elaboração. Curitiba: Ibpex, 2011. 